AUXILIARY RIFLE BARREL FOR GUNS.

Hand drilling may be seen in many of the quarries. lifted by one man operating a hoisting engine, and We give an engraving of an improvement in guns The derricks have the old iron rod guys. Boom lifting by him transferred across the river and deposited upon which permits of converting any ordinary center-fire, is unknown there, and in some of the deeper quarries a car. The conveyer is a steel wire rope two inches in breech-loading rifle into a weapon of smaller bore. a block of marble is lifted several times and by sev- diameter, anchored and resting upon "A" frame This invention consists in an auxiliary rifle barrel eral derricks before it is landed on the bank. But the braces at each end. The cable may be either level or adapted to be inserted in the ordinary gun barrel in back wardness of Vermont quarrymen in modern me- inclined as desired. The carriage travels either way the place of a cartridge, the auxiliary barrel being thods of handling stone is nowhere shown so conspicu- on the cable, being propelled by means of an endless rifled and furnished with a hinged breech eap for con- ously as in the old stone boats which are drawn about rope operated by a hoisting engine. This endlese rope fining the smaller cartridge. $\quad$ the yards and mills by the ponderous ox. The rear end of the auxiliary barrel is reduced in The quarries in the South are of more recent origin means of this rope the carriage may be stopped and diameter, and grooved longitudinally to receive the than those in the North; hence those who operate held at any point on the cable while the stone is being cartridge extractor to which the breech cap is pivoted. them seek and apply all modern improvements. In hoisted or lowered. The hoisting and conveying may and the breech cap and the cartridge extractor are inclosed in a sleeve screwed on the auxiliary barrel. The breech cap is provided, in the present case, with an oblique firing pin, but where a center-fire cartridge is used, the pin goes straight through the cap. The sleeve on the auxiliary barrel is provided with a flange corresponding to the provin of the she the auxiliary barrel is arranged to be withdrawn from the gun barrel by the usual cartridge extractor.

The cartridge in the auxiliary barrel is fired in the same manner as the ordinary cartridge, and the empty shell is removed by drawing out the cartridge extractor, the hinged breech-cap being used as a handle for the purpose.

One advantage claimed for this improveOne advantage claimed for this improve

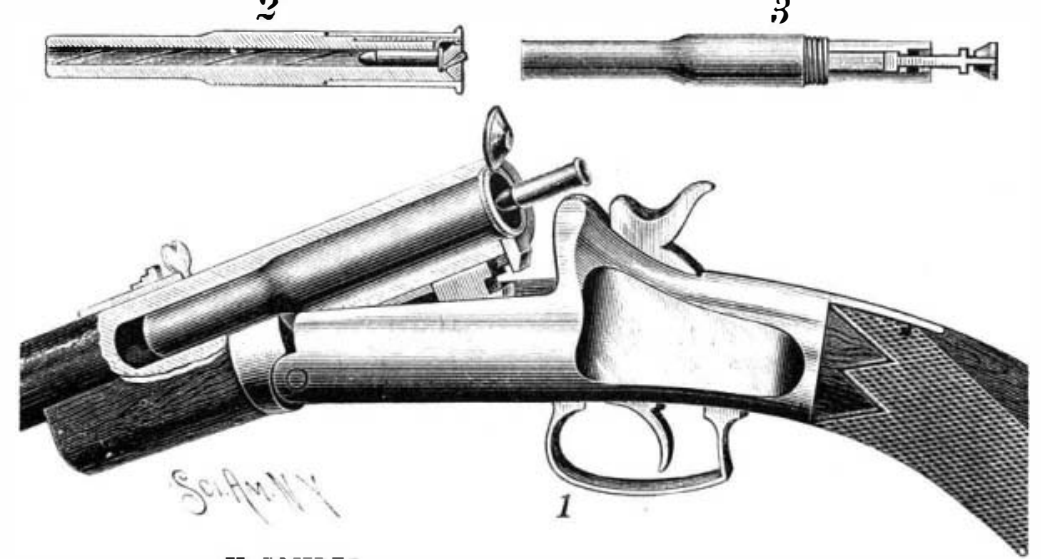

MCCANDLESS' AUXILIARY RIFLE BARREL be carried on either separately or together. in the latter case effecting a great saving in time.

The reach of one of these conveyers ex. tends at an angle of 45 degrees from the cable, by means of which stone can be dragged until it is suspended. Sometimes it is advisable to use a snatch block, by weans of which the distance of drag may be considerably extended.

While at the Brandy wine quarries I saw a man lift a large mass of stone from the quarry, run it across the river on the conveyer and deposit it on a bank there. There was no one on the other side of the river, so that the stone was dislodged by the man running the hoisting engine. The courteous and intelligent secretary of the Brandywine Co., Mr. H. M. Barksdale, informed me that this stone was of a size and kind for ary barrel and the smaller cartridges fcr small game, | some cases which have come under my observation which they had no orders at present, and they were and without any change or adjustment may withdraw the equipments have not been applied only because simply depositing it on the other side of the river in the auxiliary barrel and use the gun for the larger the foreman was from New England, and sailed in the order to get it out of the way, intending to bring it shot.

This invention has been patented by Mr. James W. McCandless, of Florence, Colorado.

\title{
NOTES ON QUARRYING.
}

$$
\begin{aligned}
& \text { TES ON QUARRYING. } \\
& \text { BY WM. L. SAUS DRS. }
\end{aligned}
$$

I have recently spent a little time at some quarries in the South, notably the extensive granite quarries of Brandywine Granite Co., on the Brandywine Creek, Wilmington, Del., and the soapstone quarries of the Albemarle Soapstone Co., North Garden, Va. It is a conspicuous fact that the quarries in the South are better equipped with machinery and with modern ap- found at the Brandywine quarries a machine at work what modified, is in use by the contractors who are
pliances than those in the North. Any one who has splitting up blocks of granite readily, economically, building the Sodom dam, and I have also seen it in made a tour of inspection through the extensive marble and satisfactorily. We got at the exact facts in regard the slate quarries at Monson, Me. There are many

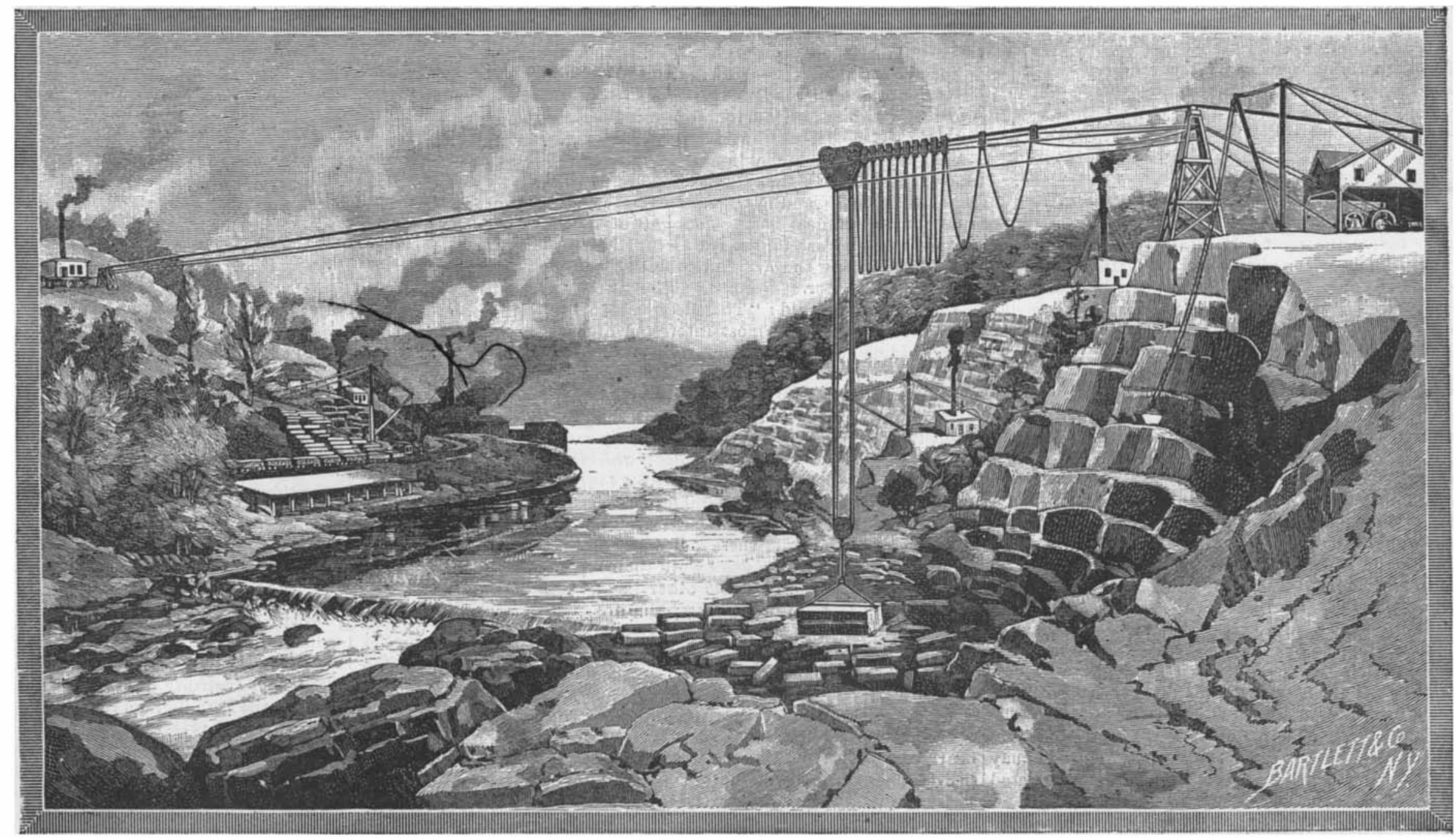

WIRE CABLE HOISTING AND CONVEYING APPARATUS AT QUARRIES OF THE BRANDYWINE GRANITE CO., WILMINGTON, DEL.

quarries of Vermont, going there with a view of entering the quarry business and of learning something, will find that, while he will be interested and instructed in what he sees, yet, if he goes through the Georgia quarries, stopping en route at the Tuckahoe deposits, Tuckahoe, N. Y., he will realize that his Vermont instruction was largely in the line of ancient history. This applies not only to the quarrying, butto the finishing of the marble. Hand channeling is still pursued fiver, though at present operations are going on only back again and use it later on. Here was a means by which a quarryman could, with but little expense, de posit his different grades of stone in different dumps on a line with each other, keeping his yard clear and which he can pick up a block at any time that will nearest conform to an order which he has in hand. That the Brandywine quarries are producing stone economically is evident from the fact that they are perience in the New England quarries, and it made
such an impression upon him that it was necessary,
the Sodom dam, on the New York aqueduct.
n order to offset it, to show him actual results. We
This same system of hoisting and conveying, some

Brazil. This statement was made by men of large ex- economies, and it made

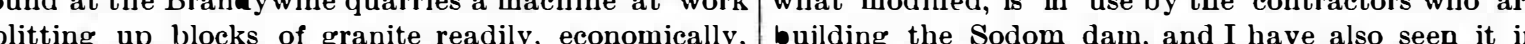
out of the rut.

I visited the Brandywine quarries with a gentl Ame purpose of st 政 (1) 